\title{
Action of AferBio (fermented food) in a rat inflammatory model
}

\author{
This article was published in the following Dove Press journal: \\ Journal of Experimental Pharmacology \\ 5 September 2012 \\ Number of times this article has been viewed
}

\author{
Anna Eliza Maciel de Faria \\ Mota Oliveira ${ }^{1,2}$ \\ Benedito Junior Lima de \\ Medeiros' \\ Hugo Alexandre Favacho' \\ José Carlos Tavares \\ Carvalho',2 \\ 'Laboratory of Drug Research, \\ College of Pharmaceutical Sciences, \\ Center for Biological and Health \\ Sciences, University of Amapá, \\ ${ }^{2}$ Graduate Program in Health \\ Sciences, Center for Biological and \\ Health Sciences, Federal University \\ of Amapá, Amapá, Brazil
}

Correspondence: José Carlos Tavares Carvalho

Rod Juscelino kubitschek, S/N, CEP

68902-689 - Macapa,

Amapá, Brazil

Tel +5509640092907

Fax +55964009 2906

Email farmacos@unifap.br
Background: AferBio is a fermented prebiotic food that contains beta-glucans, which are oligosaccharides capable of stimulating the proliferation of beneficial bacteria in the gastrointestinal tract. The aim of this study was to evaluate the possible effects of this functional food on the inflammatory response in rats.

Methods and results: AferBio $(900 \mathrm{mg} / \mathrm{kg})$ inhibited edema formation by $34 \%$ compared to the control group. We also observed inhibition of the primary and secondary reactions of inflammation after the injection of Freund's adjuvant in the animals fed AferBio. Daily administration of AferBio for $6 \mathrm{~d}$ inhibited the formation of granulomatous tissue by $37 \%$; additionally, inhibition of $31 \%$ of neutrophil migration downstream of carrageenan-induced peritonitis was observed. An ulcerogenic potency assay revealed that indomethacin produced a higher number of lesions compared to treatment with AferBio. Anti-inflammatory potency analysis showed that indomethacin inhibited $39 \%$ of carrageenan-induced edema but produced a higher number of lesions. However, animals treated with AferBio had areas of hyperemia without ulcerative lesions and $21 \%$ of edema was inhibited.

Conclusion: Based on the results obtained in this study, AferBio appears to have antiinflammatory activity during acute and chronic inflammatory processes.

Keywords: AferBio, anti-inflammatory, cell migration, prebiotics

\section{Introduction}

The study of new anti-inflammatory drugs is very important, especially those that relate to use in chronic inflammatory states. In this context, functional foods are important, but need to be studied with the same rigor as synthetic drugs.

Bacterial microbiota are acquired shortly after birth, remain relatively stable throughout life, and are essential to overall homeostasis. It is known that bacterial microbiota are important for normal intestine development, immune maintenance, and the stimulation of cytoprotective responses. They also play an important role in health-related functions of the host, such as protection against viruses and harmful bacteria. ${ }^{1}$

Although environmental factors and host genetics contribute to microbiota formation, diet seems to be a major factor in regulating microorganism species that colonize the intestine. ${ }^{2}$ Therefore, consuming food that stimulates the proliferation of beneficial bacterial species in the gastrointestinal (GI) tract is a very attractive option for restoring microbial balance and preventing disease. ${ }^{3}$

Functional foods, by definition, are ordinary foods that have specific health benefits, such as disease-prevention properties and an improvement of general well-being. 
These benefits are due to the presence of physiologically healthy ingredients that promote proliferation of beneficial bacteria in the GI tract. These species restore the microbial balance and increase the immune system's ability to fight pathogens. ${ }^{3}$

Foods with beneficial properties have been used by many cultures. Prebiotics have been used in food preservation and preparation since antiquity. ${ }^{4}$ Recently, the low incidence of disease observed in some societies has been attributed to diet, increasing the amount of research and investment in this area. ${ }^{5}$

Prebiotics are nondigestible substances that provide physiological benefits to the host. When consumed in adequate amounts, they selectively stimulate the growth of colonic microbiota, which provides health benefits to the individual. ${ }^{6}$ This is thought to have beneficial effects on nutrition and intestinal maintenance, as well as treatment of inflammation, functional disorders, and other extraintestinal diseases.

Several studies have shown effects of prebiotics and probiotics on the immune systems of individuals of all ages. These substances have been very useful in the prevention and treatment of inflammatory bowel disease and atopic dermatitis, as well as other pathogens. ${ }^{7,8}$ It is assumed that these foods introduce beneficial bacteria that fight invading pathogens during chronic inflammation and cell migration. However, there is a lack of scientific studies on the involvement of prebiotic foods in inflammatory mechanisms. Based on data regarding the increased use of such foods in the diets of many societies, we evaluated the activity of a fermented food powder classified as a prebiotic and marketed in Brazil under the commercial name AferBio. Preliminary studies have confirmed that its anti-ulcerogenic activity is related to prostaglandin synthesis. ${ }^{9}$

AferBio is a Brazilian fermented food powder composed of soy, wheat, and organic wheat germ. It is a mixture of nonsoluble and fermentable fibers rich in oligosaccharides, which are beta-glycans with prebiotic properties. Zinc, vitamin $\mathrm{B} 12$, and selenium, produced in the fermentation process, are also present.

We evaluated the effects of consumption of fermented food on acute and chronic inflammatory processes and ulcerogenic activity.

\section{Material and methods \\ AferBio}

The fermented food powder, AferBio, was provided by the company AferBio Bioalimentos, Ltd (Santa Barbara D’Oeste, São Paulo, Brazil, Brazilian Sanitary Surveillance
Agency - ANVISA Operating Permit No 6.04980-1). The production date was September 2010, and the expiration date was September 2012.

\section{Animals}

This study was approved by the Ethics Committee of the Federal University of Amapá (CEP - UNIFAP - 004A/2011). All procedures were performed according to the International Committee for animal care in accordance with established national regulations for animal experimentation.

The experiments were performed using male albino Wistar rats (240-280 g) provided by the Central Laboratory of the State of Amapá - Macapá (LACEN/AP). Each experimental group was composed of 5 animals. They were kept in polyethylene cages on a temperature-controlled rack $\left(25^{\circ} \mathrm{C} \pm 2^{\circ} \mathrm{C}\right)$ under a 12-hour light-dark cycle. They had free access to food and water, except for the 24 hours before the experiments, when they had access only to water.

\section{Drug administration}

The dose of AferBio used in the experiments was $900 \mathrm{mg} / \mathrm{kg} / \mathrm{d}$ (oral) and was decided upon based on studies performed by Possenti et al, where this dose was established for human use. ${ }^{9}$

Control treatments (distilled water and indomethacin) were given orally at different times after inflammation induction. AferBio was administered for 30 days before inflammation induction. For the granuloma test, AferBio was administered 30 days before and 2 hours after pellet implantation, followed by daily treatment for 6 days.

\section{Evaluation of AferBio in models of inflammation}

\section{Carrageenan-induced paw edema}

The technique used to measure edema was based on the method described by Carvalho et al. ${ }^{10}$ Different groups of rats were orally pretreated ( $n=5 /$ group) with distilled water, the non-steroidal anti-inflammatory (NSAID) indomethacin $(10 \mathrm{mg} / \mathrm{kg})$ (Merck \& Co, Inc, Whitehouse Station, NJ), and AferBio ( $900 \mathrm{mg} / \mathrm{kg} / \mathrm{d})$. Next, a subplantar injection of $0.1 \mathrm{~mL}$ of $1 \%$ carrageenan (solubilized in saline, Iota-carrageenan, Fluka-Biochemika, Buchs, Switzerland) was administered in the right hind paw of each rat to induce edema; an equal volume of saline was injected into the left hind paw as a control treatment. Paw volume was measured using a plethysmometer (Ugo Basile, Collegeville, PA) before treatment and every hour after for a total of 6 hours. 


\section{Freund's adjuvant-induced arthritis fluka}

Arthritis was induced using the method described by Newbould, ${ }^{11}$ which consists of a 0.1 -mL injection of Freund's complete adjuvant (Sigma Aldrich, St Louis, MO) into the plantar region of the right hind paw. Control treatment consisted of injection of an equal volume of saline into the left hind paw. The characteristic clinical signs of arthritic response were investigated from the seventh day after the application of adjuvant. ${ }^{11}$

Three groups of rats ( $n=5 /$ group) were orally treated with AferBio $(900 \mathrm{mg} / \mathrm{kg})$, indomethacin $(10 \mathrm{mg} / \mathrm{kg})$, or distilled water $(0.5 \mathrm{~mL})$ beginning 30 minutes after a $0.1-\mathrm{mL}$ injection of $5 \%$ Freund's complete adjuvant, for 30 days.

Edema measurement was performed every 3 days at the same time (10 am) using a plethysmometer as described above.

\section{Induction of granulomatous tissue}

The method used was previously described by Meier et al ${ }^{12}$ and Niemegeers et al. ${ }^{13}$ Briefly, different groups of rats $(n=5 /$ group) were orally treated with distilled water $(0.5 \mathrm{~mL})$ or dexamethasone $(0.2 \mathrm{mg} / \mathrm{kg}) 2$ hours after pellet implantation. A third group was treated with AferBio $(900 \mathrm{mg} / \mathrm{kg})$ for 30 days before and 6 days after pellet implantation On the 7th days, animals were sacrificed in a $\mathrm{CO}_{2}$ chamber, granulomas were removed, and the weight of each granuloma was calculated based on the difference between the initial and final dry weights.

\section{Carrageenan-induced peritonitis in rats}

The method used was described by Carvalho et al. ${ }^{10}$ At 30 minutes before carrageenan injection, 2 groups of rats ( $n=5 /$ group) were orally treated with dexamethasone (EMS Industria Farmaceutica, Sau Paulo, Brazil. $0.5 \mathrm{mg} / \mathrm{kg}$ ) or distilled water $(0.5 \mathrm{~mL})$. A third group had been pretreated for 30 days with AferBio $(900 \mathrm{mg} / \mathrm{kg} / \mathrm{d})$. All groups were given an injection of carrageenan, and cell migration was evaluated 4 hours later.

\section{Combined test: rat paw edema and gastric lesions}

Lesions and inflammation were induced using the method described by Rainsford and Whitehouse ${ }^{14}$ with slight modifications. Different groups of rats ( $n=5 /$ group) were fasted for 24 hours (they had free access to water). The animals were then treated orally with distilled water $(0.5 \mathrm{~mL})$, indomethacin $(10 \mathrm{mg} / \mathrm{kg})$, or were pretreated with AferBio for 30 days $(900 \mathrm{mg} / \mathrm{kg} / \mathrm{d})$. After treatment, the animals were subjected to stress for 17 hours based on the technique described by
Basile et al. ${ }^{15} \mathrm{Next}, 0.1 \mathrm{~mL}$ of $1 \%$ carrageenan was injected into the subplantar area of the right paw, and the same volume of saline was injected into the left paw. Edema was determined 2.5 hours later using a plethysmometer (Model 7140), and the lesion grade was determined using the method described by Basile et al. ${ }^{15}$

\section{Statistical analysis}

For statistical analyses, we performed one-way analysis of variance and applied the Student-Newman-Keuls test using the software SigmaPlot ${ }^{\circledR}$ version 10.0. Results were considered significant at $P<0.05$ and are reported as the mean \pm standard error of the mean.

\section{Results}

\section{Carrageenan-induced paw edema}

AferBio $(900 \mathrm{mg} / \mathrm{kg} / \mathrm{d})$ produced an inhibitory effect at the peak of edema; $34 \%$ inhibition was observed after 4 hours when compared with the group treated with distilled water (negative control, $P<0.05$, Figure 1). Indomethacin $(10 \mathrm{mg} / \mathrm{kg})$ treatment resulted in $40 \%$ inhibition.

\section{Freund's adjuvant-induced arthritis}

From the seventh day after the application of adjuvant, the animals showed the presence of lymph nodes characteristic of the arthritic response, and AferBio $(900 \mathrm{mg} / \mathrm{kg})$ significantly inhibited $(P<0.05)$ the primary and secondary reactions triggered by Freund's adjuvant injection from days 3 through 30. A similar result was observed for indomethacin $(10 \mathrm{mg} / \mathrm{kg}$ ) (Figure 2).

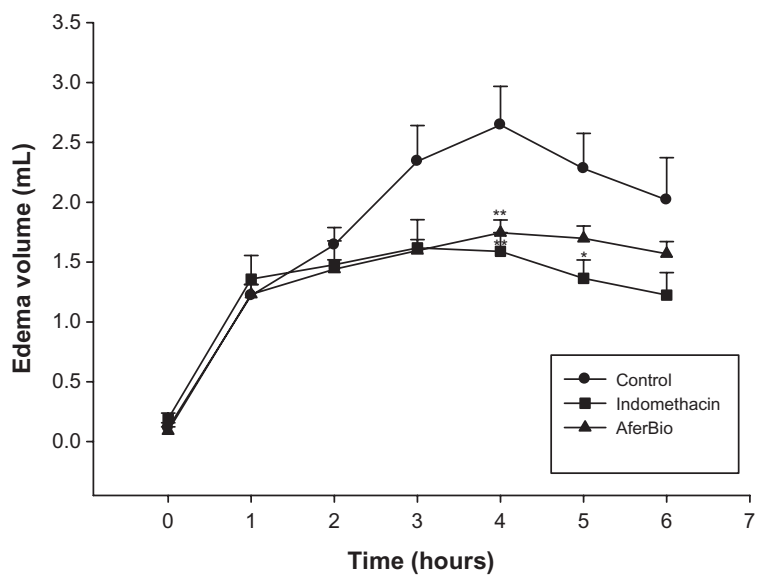

Figure I Effect of AferBio $(900 \mathrm{mg} / \mathrm{kg} / \mathrm{d}$ for $30 \mathrm{~d}$ before induction) and indomethacin $(10 \mathrm{mg} / \mathrm{kg})$ on rat paw edema induced by intraplantar injection of carrageenan (1000 $\mu \mathrm{g} / \mathrm{paw})$.

Notes: $* P<0.05 ; * * P<0.01$. Each value represents the mean \pm SEM ( $n=5$ /group). 


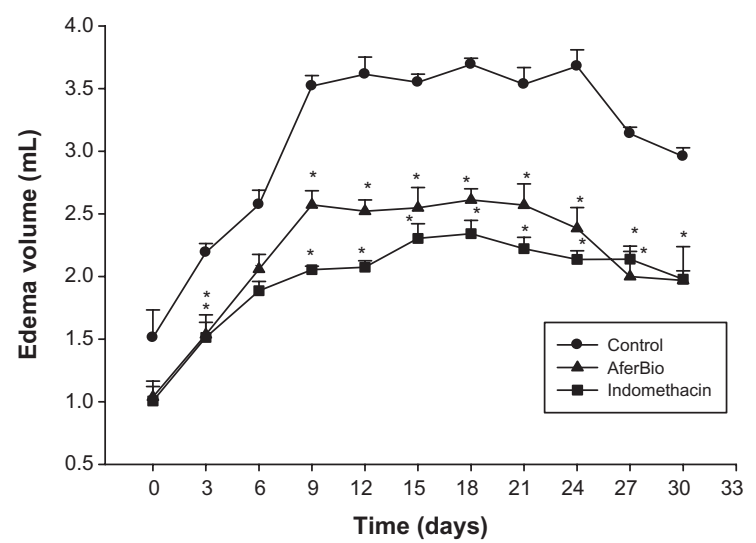

Figure 2 Effect of AferBio $(900 \mathrm{mg} / \mathrm{kg} / \mathrm{d})$ and indomethacin $(10 \mathrm{mg} / \mathrm{kg})$ on arthritis induced by intraplantar injection of $5 \%$ Freund's adjuvant $(0.1 \mathrm{~mL})$.

Notes: $* p<0.05$. Each value represents the mean \pm SEM $(n=5 /$ group $)$.

\section{Induction of granulomatous tissue}

Daily administration of AferBio $(900 \mathrm{mg} / \mathrm{kg}$ ) during the 6 days period prior to pellet implantation inhibited the formation of granulomatous tissue by $37 \%$ as compared to the group treated with distilled water. In comparison, rats treated with dexamethasone $(0.5 \mathrm{mg} / \mathrm{kg}$ orally) showed $62 \%$ inhibition $(P<0.01$, Figure 3).

\section{Carrageenan-induced peritonitis in rats}

The group treated with AferBio $(900 \mathrm{mg} / \mathrm{kg}$ ) showed $31 \%$ inhibition of neutrophil migration. However, the group treated with dexamethasone $(0.5 \mathrm{mg} / \mathrm{kg})$ showed $56 \%$ inhibition of neutrophil migration. Leukocyte migration inhibition was significant in both AferBio and dexamethasone treatment groups when compared to the control group $(P<0.05)$, suggesting possible involvement of AferBio components with the mechanisms involved in leukocyte migration (Figure 4).

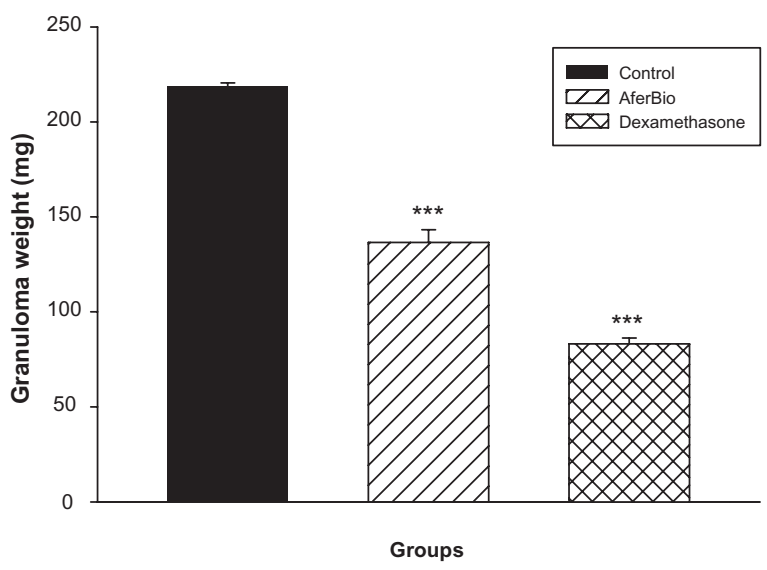

Figure 3 Effect of AferBio ( $900 \mathrm{mg} / \mathrm{kg} / \mathrm{d}$ for $30 \mathrm{~d}$ before) and dexamethasone $(0.5 \mathrm{mg} / \mathrm{kg}$ for $6 \mathrm{~d}$ before) on the formation of granulomatous tissue. Notes: The bars represent the mean \pm SEM ( $n=5$ /group). *** $P<0.001$.

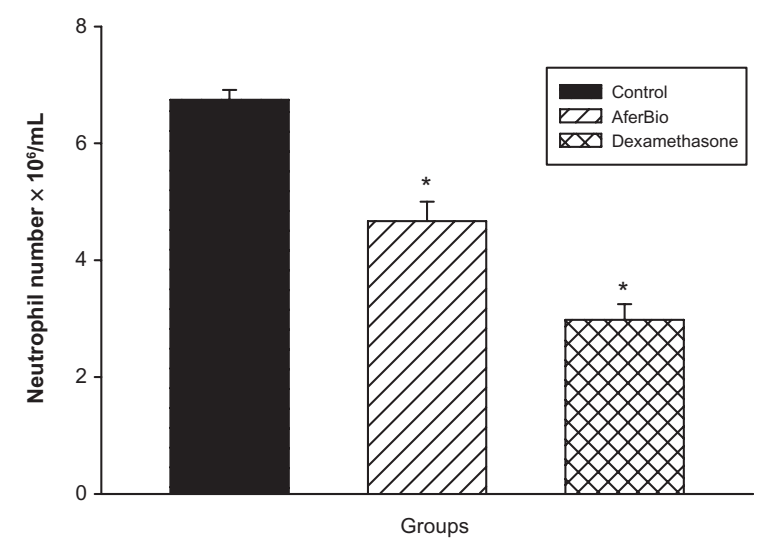

Figure 4 Effect of AferBio $(900 \mathrm{mg} / \mathrm{kg} / \mathrm{d}, 30$ days before induction) and dexamethasone $(0.5 \mathrm{mg} / \mathrm{kg})$ on neutrophil migration into the peritoneal cavity stimulated by $3 \mathrm{~mL}$ of carrageenan $(100 \mu \mathrm{g} / \mathrm{mL})$.

Notes: Each bar represents the mean \pm SEM of the number of neutrophils $(n=5$ / group). $* P<0.05$.

\section{Combined test: rat paw edema and gastric lesions}

In this study, GI lesion evaluation showed that animals treated with indomethacin $(10 \mathrm{mg} / \mathrm{kg})$ had a higher number of lesions than animals treated with AferBio $(900 \mathrm{mg} / \mathrm{kg})$ (Table 1 and Figures 5-7).

An evaluation of anti-inflammatory action revealed that indomethacin inhibited carrageenan-induced edema by approximately $39 \%$, but it produced a higher number of lesions. In animals treated with AferBio $(900 \mathrm{mg} / \mathrm{kg})$, lower numbers of severe and invasive lesions (type 3) and small erosions (type 2) were observed. In this group, areas of hyperemia were prevalent and the edema was inhibited by $21 \%$ (Figure 8 ).

\section{Discussion}

The possibility of preventing or decreasing inflammatory processes through the daily administration of highly effective food with therapeutic properties and low side effects is an attractive alternative to pharmaceutical therapy.

Table I Effect of AferBio ( $900 \mathrm{mg} / \mathrm{kg} / \mathrm{d}, 30$ days before induction), water, and indomethacin on the incidence of stress-related acute gastric lesions produced ( 17 hours) using the models restriction and immersion in water

\begin{tabular}{lllllll}
\hline Treatment & $\mathbf{n}$ & Dose & \multicolumn{3}{l}{ Types of lesions } & \multirow{2}{*}{$\begin{array}{c}\text { Ulcer } \\
\text { index }\end{array}$} \\
\cline { 4 - 6 } & & & $\mathbf{I +}$ & $\mathbf{2 +}$ & $\mathbf{3 +}$ & \\
\hline Water & 5 & $0.5 \mathrm{~mL}$ & $29 \pm 5$ & $18 \pm 2$ & $5 \pm 0.8$ & 16 \\
AferBio & 5 & $900 \mathrm{mg} / \mathrm{kg}$ & $22 \pm 2$ & $9 \pm 0.6^{\mathrm{b}}$ & $4 \pm 0.6$ & 10 \\
Indomethacin & 5 & $10 \mathrm{mg} / \mathrm{kg}$ & $21 \pm 4$ & $21 \pm 4$ & $17 \pm 3^{\mathrm{a}}$ & 23 \\
\hline
\end{tabular}

Notes: The numbers represent the mean \pm SEM $\left(n=5 /\right.$ group); ${ }^{\text {asignificant }}$ difference from control $(P<0.05)$; significant difference from indomethacin and control $(P<0.05)$. 


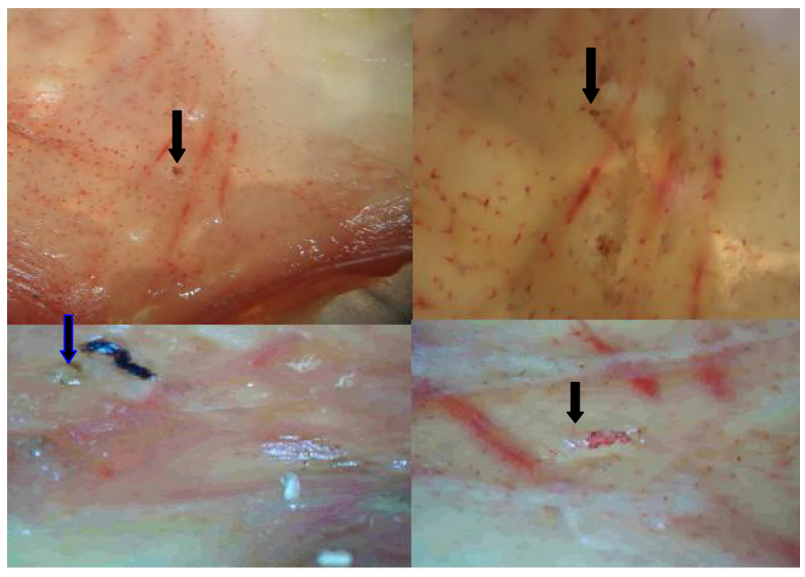

Figure 5 Gastric mucosa of animals pretreated with AferBio $(900 \mathrm{mg} / \mathrm{kg} / \mathrm{d})$ for 30 days before being subjected to stress.

Note: Arrows indicate discrete lesions, petechiae, and areas of hyperemia.

AferBio $(900 \mathrm{mg} / \mathrm{kg} / \mathrm{d})$ administered orally for a period of $30 \mathrm{~d}$ before and $6 \mathrm{~d}$ after carrageenan injection significantly inhibited edema formation with kinetics similar to the positive control indomethacin (Figure 1). It can be postulated that this pharmacological property is attributable to the inhibition of proinflammatory mediator release, especially the release of prostaglandins. The effect of AferBio on edema was similar to that of indomethacin.

Freund's complete adjuvant was used to induce rheumatoid arthritis because it reproduces symptoms in rats that are observed in humans. This compound contains a mycobacterium capable of damaging articular and hyaline cartilage. ${ }^{16}$

Figure 2 shows the inflammatory response 30 days after intraplantar of Freund's adjuvant in the rat hind paw. The edema volume was significantly higher in the group treated with distilled water (negative control) compared to the groups treated with indomethacin and AferBio.

The control group showed a more intense chronic inflammatory reaction after injection of Freund's adjuvant, which resulted in rheumatoid arthritis. Groups treated with indomethacin and AferBio had less intense reactions, but the group

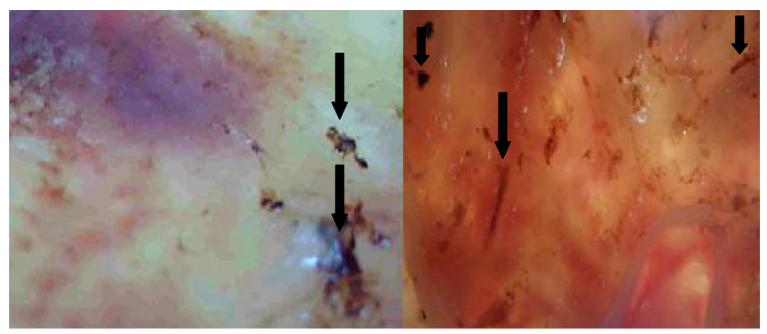

Figure 6 Gastric mucosa of animals treated with indomethacin ( $10 \mathrm{mg} / \mathrm{kg}$, orally) and subjected to fasting and stress.

Note: Arrows indicate numerous severe lesions type 3.

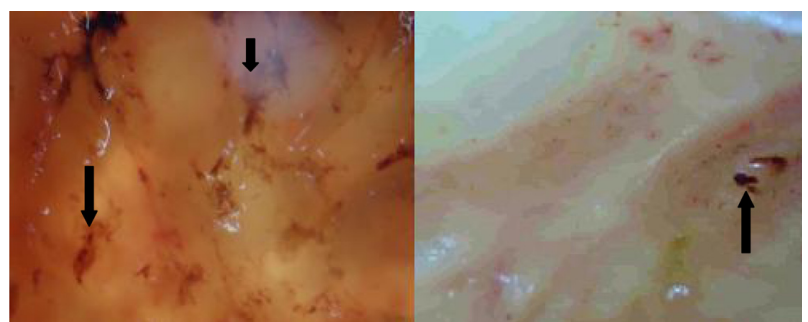

Figure 7 Gastric mucosa of animals treated with distilled water and subjected to fasting and stress.

Note: Arrows indicate hyperemia and lesions type 2.

treated with indomethacin showed more resistance. Based on these observations, we suggest that AferBio regulates the mechanisms triggered by the injection of Freund's adjuvant.

Cotton pellet-induced granuloma is a model of chronic inflammation. Granulomas are nodules of hypertrophic granulation tissue composed mainly of accumulated fluid, proteins, macrophages, and fibroblasts; their formation is mediated by many molecules, including cytokines, chemokines, and eicosanoids. ${ }^{17}$ Oral daily administration of AferBio for 30 days before and 6 days after edema induction significantly inhibited $37 \%$ of granulomatous tissue formation; $62 \%$ inhibition was observed in the group treated with dexamethasone (Figure 3 ). These inhibitory results were highly significant $(P<0.001)$ compared to those of the control group treated with distilled water, showing that AferBio had an effect similar to that of the steroidal antiinflammatory compound.

Steroidal anti-inflammatory agents modify inflammatory reactions, typically by inhibiting prostaglandin and thromboxane synthesis through phospholipase A2 inhibition. ${ }^{18,19}$

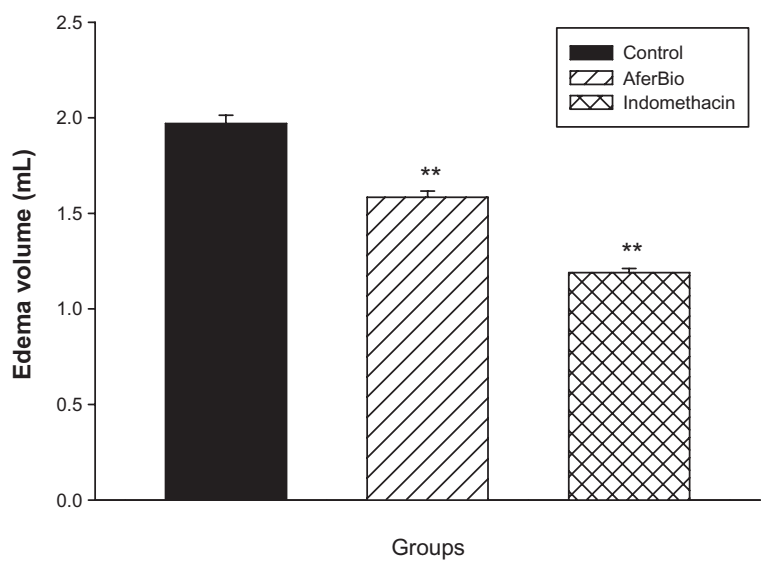

Figure 8 Effect of administration of AferBio $(900 \mathrm{mg} / \mathrm{kg} / \mathrm{d}, 30 \mathrm{~d}$ before induction, orally), indomethacin $(10 \mathrm{mg} / \mathrm{kg}$, orally), and distilled water $(0.5 \mathrm{~mL}$, orally) on edema triggered by intraplantar injection of $1 \%$ carrageenan $(0.1 \mathrm{~mL}$, measured 2.5 hours after injection) after stress testing (immersion bath) for 17 hours. Notes: ${ }^{* * P}<0.01$. Each bar represents the mean \pm SEM $(n=5 /$ group $)$. 
The results presented here reflect the effectiveness of AferBio in preventing granulation tissue formation.

Gastric cytoprotection is a property of certain substances, including prostaglandins. Non-antisecretory doses of these compounds help protect the gastric mucosa against inflammation and necrosis during exposure to harmful agents. ${ }^{10}$

In a previous study using a model of ethanol-induced ulcers in Wistar rats, AferBio increased gastroprotective mucus and antiulcer activity in ethanol-treated animals. ${ }^{9}$ The mechanism of AferBio antiulcer activity appeared to be related to its ability to interfere with gastric cytoprotection control mechanisms; increased synthesis or decreased degradation of prostaglandin can result in increased gastroprotective mucus secretion. Studies examining anti-secretory activity in rats and intestinal motility in mice revealed that fermented food does not interfere with mechanisms that control gastric secretion, suggesting that protection is associated with increased gastroprotective mucus secretion. ${ }^{9}$

A method of ulcer induction resulting from water immersion-derived stress can be used to evaluate the potential of certain drugs to cause stomach ulcers. The stress test paradigm induced gastric lesions, and animals treated with indomethacin had a greater number of high-grade lesions (Table 1). Discrete lesions and areas of hyperemia were prevalent in animals treated with AferBio, suggesting once again that protection of the gastric mucosa is associated with AferBio administration.

Lesion formation evaluation showed that indomethacin inhibited $39 \%$ of carrageenan-induced edema after 2.5 hours. However, the animals in this group had a higher number of invasive lesions and points of erosion, confirming that the prolonged use of NSAIDs can provoke gastric mucosa irritation, hemorrhage, and lesions. In the group treated with AferBio, inhibition of edema was lower (21\%), but the animals presented with fewer, less severe lesions. Although AferBio decreases carrageenan-induced edema, it does not cause gastric mucosal damage as NSAIDs do.

The ability of cells to migrate is a fundamental process that occurs in all living organisms. In vertebrates, cell migration occurs during many biological processes..$^{20,21}$

Neutrophils play a key role in the innate immune system. In response to chemotactic stimuli, neutrophils rapidly migrate to the site of aggression to provide the first line of host defense against bacteria and other pathogens. ${ }^{22}$

The ability of AferBio to inhibit leukocyte migration into the peritoneal cavity after carrageenan-induced inflammation was evaluated in this study. This inhibition of polymorphonuclear cell migration may be related to the inhibition of the production of chemotactic substances and/or by the inhibition of adhesion molecule expression. ${ }^{23}$

Carrageenan stimulated the inflammatory process and caused cell migration into the peritoneal cavity and the production of exudates rich in polymorphonuclear cells 4 hours after injection. The group treated with the steroid dexamethasone showed $56 \%$ inhibition of cell migration compared to the control group. In contrast, $31 \%$ inhibition was observed in the group treated with AferBio, suggesting a possible role of food compounds in polymorphonuclear cell migration.

\section{Conclusion}

Our results reveal that AferBio had significant effects in both acute and chronic models of inflammation. These findings suggest that prolonged consumption of prebiotic foods may disrupt pathophysiological mechanisms, eg, the effects of prebiotics on mediators derived from arachidonic acid.

\section{Acknowledgments}

This work was supported by a post-graduate fellowship from Conselho Nacional de Desenvolvimento Científico e Tecnológico - CNPq.

\section{Disclosure}

No competing financial interests exist. All the authors have substantially participated in the investigation, data analysis, and the preparation of the manuscript and accept full responsibility for its content.

\section{References}

1. Quigley EM. The use of probiotics in functional bowel disease. Gastroenterol Clin North Am. 2005;34(3):533-545.

2. Penner R, Fedorak RN, Madsen KL. Probiotics and nutraceuticals: nonmedicinal treatments of gastrointestinal diseases. Curr Opin Pharmacol. 2005;5(6):596-603.

3. Alvarez-Olmoz MI, Oberhelman RA. Probiotics agents and infectious diseases: A modern perspective on a traditional therapy. Clin Infect Dis. 2001;32(11):1467-1576.

4. Reid G, Bruce AW, Fraser N, Heinemann C, Owen J, Henning B. Oral probiotics can resolve urogenital infections. FEMS Immunol Med Microbiol. 2001;30(1):49-52.

5. Matsubara S. Alimentos funcionais. Industria de Laticinios. Journal of Dairy Industry. 2001;6(34):10-18.

6. Reid G. How science will help shape future clinical applications of probiotics. Clin Infect Dis. 2008;46 Suppl 2:S62-S66.

7. Lenoir-Wijnkoop I, van Aalderen WM, Boehm G, Klaassen D, Sprikkelman AB, Nuijten MJ. Cost-effectiveness model for a specific mixture of prebiotics in The Netherlands. Eur J Health Econ. 2010;13(1):101-110.

8. Quigley EM. Prebiotics and probiotics; modifying and mining the microbiota. Pharmacol Res. 2010;61(3):213-218.

9. Possenti A, et al. Atividade antiulcerogênica e mecanismo de ação de alimento Fermentado à base de trigo e soja utilizado como alimento Funcional. GED gastroenterol.endosc.dig. 2011;30(4):125-131. 
10. Carvalho JC, Sertié JA, Barbosa MV, et al. Anti-inflammatory activity of the crude extract from the fruits of Pterodon emarginatus Vog. J Ethnopharmacol. 1999;64(2):127-133.

11. Newbould BB. Chemotherapy of arthritis induced in rats by mycobacterial adjuvant. Br J Pharmacol Chemother. 1963;21:127.

12. Meier R, Schuler W, Desaulles P. L-usnic acid: tumor inhibitor isolated from Lichens. Experimentia. 1950;31(6):625.

13. Niemegeers CJ, Awouters F, Lenaerts FM, Janssen PA. The activity of suprofen on nystatin-induced paw oedema in rats. Arzneimittelforschung. 1975;25(10):1516-1519.

14. Rainsford KD, Whitehouse MW. Non-steroid antiinflammatory drugs: Combined assay for anti-edemic potency and gastric ulcerogenesis in the same animal. Life Sci. 1977;21(3):371-378.

15. Basile AC, et al. Pharmacological assay of Casearia sylvestris. I: Preventive anti-ulcer activity and toxicity of the leaf crude extract. J Ethnopharmacol. 1990;30(2):185-197.

16. Hegen M, Keith JC Jr, Collins M, Nickerson-Nutter CL. Utility of animal models for identification of potential therapeutic for rheumatoid arthritis. Ann Rheum Dis. 2008;67(11):1505-1515.

17. Ghaisas MM, Dandawate PR, Zawar SA, Ahire YS, Gandhi SP. Antioxidant, antinociceptive and anti-inflammatory activities of atorvastatin and rosuvastatin in various experimental models. Inflammopharmacology. 2010;18(4):169-177.
18. Little RJ, Bodor N, Loftsson T. Soft drugs based on hydrocortisone: the inactive metabolite approach and its application to steroidal agents. Pharm Res. 1999;16(6):961-967.

19. Barnes JP. How corticosteroids control inflammation: Quintiles Prize Lecture. Brit J Pharmacol. 2005;148(3):245-254.

20. Ridley AJ, Schwartz MA, Burridge K, et al. Cell migration: integrating signals from front to back. Science. 2003;302(5651):1704-1709.

21. Lee KH, Choi EM. Analgesic and anti-inflammatory effects of Ligularia fischeri leaves in experimental animals. J Ethnopharmacol. 2008;120(1):103-107.

22. Aerbajinai W, Liu L, Chin K, Zhu J, Parent CA, Rodgers GP. Glia maturation factor- $\gamma$ mediates neutrophil chemotaxis. J Leukoc Biol. 2011;90(3):529-538.

23. Vargas Junior A. Evaluation of anti-inflammatory activity of extracts of Passiflora alata Dryander and Passiflora edulis Sims in the model of carrageenan-induced pleurisy in mice. 155f. (Masters dissertation) Pharmacy Graduate Program, Federal University of Santa Catarina, Florianópolis, 2005
Journal of Experimental Pharmacology

\section{Publish your work in this journal}

The Journal of Experimental Pharmacology is an international, peerreviewed, open access journal publishing original research, reports, reviews and commentaries on all areas of laboratory and experimental pharmacology. The manuscript management system is completely online and includes a very quick and fair peer-review system.

\section{Dovepress}

Visit http://www.dovepress.com/testimonials.php to read real quotes from published authors. 